\title{
A constituição da identidade no vestibular indígena: diferença, desigualdade e diversidade
}

\section{The constitution of the identity in the indigenous vestibular: difference, inequality and diversity}

Ismara TASSO*

UEM

\section{Raquel Fregadolli GONÇALVES ${ }^{* *}$ \\ UEM}

Resumo: A diferença, a desigualdade e a diversidade estão em contradição nas práticas sociais, em função de como essas noções são discursivizadas e significadas em políticas públicas de preservação e de inclusão dos indígenas no ensino superior. Os equívocos causados pela inconsistência do termo/conceito diversidade apontam para a efetivação parcial da cidadania e para o desprestígio das identidades indígenas como parte constitutiva da identidade nacional. Sob essa inquietação, este trabalho tem por objetivo compreender o modo como as redações, produzidas pelos candidatos no $X$ Vestibular para os Povos Indígenas no Paraná (2010), imprimem a contradição da identidade linguística do indígena - ora como possibilidade de (co)existência da(s) diferença(s), ora sob efeito da desigualdade, inferioridade e tutela das ações do Estado. Para tanto, pautamo-nos no escopo teórico da Linguística, dos Estudos Culturais e da Análise do Discurso, orientada pelas noções foucaultianas. Os resultados indicam que a inconsistência de definição do termo diferença produz efeito(s) como exclusão, intolerância e, principalmente, desrespeito ao indígena. O paradoxo sob o qual a diferença é discursivizada fragiliza o teor do princípio de igualdade que rege a Diversidade Cultural e a cidadania.

Palavras-chave: Identidade. Vestibular Indígena. Diversidade Cultural. Contradição.

\begin{abstract}
Difference, inequality and diversity are at contraditions in social practices, in terms of how these notions are signified and discursivised in public policy of preservation and inclusion of indigenous in higher education. The mistakes caused by the inconsistency of the term/concept «diversity» point to the partial effective of the indigeneous citizenship and to the discredit of their identity as a constitutive part of national identity. Under this concern, this study aims at understanding how the essays produced by candidates in $X$ Vestibular para os Povos Indígenas no Paraná (2010), impress the contradiction of the linguistic identity of the indigenous - sometimes as possibility of (co) existence of (s) difference (s), sometimes under the effect of inequality, inferiority and supervision
\end{abstract}

\author{
${ }^{*}$ Doutora em \\ Linguística e \\ Língua Portuguesa. \\ ievstasso@geduem. \\ com.br \\ ${ }^{* *}$ Mestre em Letras. \\ raquelfregadolli@ \\ geduem.com.br
}


of government actions. To this end, we are referring to the theoretical scope of linguistics, Cultural Studies and Discourse Analysis, driven by Foucault's notions. The results indicate that the inconsistency of the definition of «difference» takes effect(s) as exclusion, intolerance and mainly disrespect to the indigenous. The paradox under which the difference is taken as a discourse weakens the strength of the principle of equality which governs Cultural Diversity and the citizenship.

Keywords: Identity. Indigenous Vestibular. Cultural Diversity. Contradiction.

\section{Introdução}

Dar visibilidade ao que se conforma como diverso é uma tarefa árdua e complexa, em razão de a diversidade compreender questões de difícil solução, em especial, aquelas que envolvem conflitos e tensões emergentes do convívio entre identidades contrastantes. No âmbito cultural e político, a coexistência das identidades repercute no social por relações de inclusão e de exclusão, uma vez que essas relações são submetidas a vetores de força que estratificam os sujeitos da diversidade. Os discursos circunscritos à temática da inclusão e da exclusão têm mobilizado o GEDUEM (Grupo de Estudos de Análise do Discurso da UEM) à promoção de debates, reflexões, pesquisas e produções científicas, e como fruto dos estudos e pesquisas realizados por esse grupo, este artigo tem por ponto de partida a dissertação de mestrado intitulada Cidadania, inclusão e biopolítica: $a$ identidade linguística do indígena em contradição no processo seletivo Vestibular dos Povos Indígenas no Paraná (2012) ${ }^{1}$ e, por continuidade, o desafio de discutir e refletir acerca da inconsistência dos sentidos produzidos pelo emprego do termo diferença, dado que a ele se encontram relacionados os fatores sociopolíticos e culturais da exclusão, da intolerância e, principalmente, do desrespeito ao indígena. Sob tal perspectiva, cria-se o paradoxo sob o qual a diferença é discursivizada, cujos efeitos colocam em fragilidade o teor do princípio de igualdade que rege a Diversidade Cultural e a cidadania.

Assim delineado, o olhar que aqui se estabelece sobre a educação superior indígena tem por foco duas questões: (i) o processo seletivo do vestibular específico para os indígenas; e (ii) as redações produzidas nesse mesmo processo. Vale observar que, no caso desse Vestibular, os critérios de seleção são estabelecidos de forma similar aos do vestibular convencional que classificam e determinam a aprovação do candidato. Embora o processo seletivo se configure nesses moldes e revele "certa” contradição entre uma política que deseja incluir a todos e uma prática de ingresso à universidade limitada que restringe essa possibilidade, ele é entendido como o ato solene que cria as condições à cidadania para o indígena que pleiteia uma vaga ao ensino superior. Já as redações, constituem um instrumento de avaliação e um dispositivo político educacional, e, como tal,

\footnotetext{
${ }^{1}$ Dissertação de mestrado, defendida em setembro/2012, na Universidade Estadual de Maringá (UEM), sob orientação da professora Ismara Tasso. O estudo teórico analítico que ora apresentamos configura-se em um avanço dessa dissertação compondo um projeto maior intitulado "Práticas Discursivas, verdade e biopolítica em (in)visibilidades: corpo, língua e território".
} 
efetiva-se por meio de "estratégias de relação de força sustentando tipos de saber e sendo sustentadas por eles" (FOUCAULT, 1993, p. 246). Desse modo, o que está em jogo nas redações é a valoração que lhe é atribuída, pois compreende uma parte significativa da nota total da prova, razão de possibilidade ou não de aprovação do indígena no ensino superior.

Em sentido amplo, a aprovação de um candidato ao ensino superior é coroada de atributos pelos diversos segmentos da sociedade, porque se concebe que esse sujeito possui maturidade e excelência nos saberes escolares exigidos na realização desse exame. Dessa forma, ser aprovado no vestibular implica o efeito de plena acolhida, de integração e de respeito ao sujeito universitário ingressante. Entretanto, o universitário indígena ingressante defronta-se, de imediato e durante sua permanência no espaço institucional da universidade, com inúmeros obstáculos decorrentes das diferenças culturais, sejam eles entre os próprios membros do corpo discente ou entre os universitários indígenas e corpo docente da instituição do ensino superior (IES), já que essas universidades são, essencialmente, destinadas a todos e não somente a indígenas.

Diante disso, este trabalho se justifica pela necessidade de olhar com acuidade os conceitos atribuídos ao termo diferença, discursivisados em políticas de inclusão, a fim de compreender os conflitos e as tensões que o emprego desse termo gera nas relações sociopolíticas, culturais e educacionais entre indígenas e não indígenas. Nesse intuito é que buscamos discutir e refletir sobre o modo como o termo/conceito diferença se inscreve sob o jugo das contradições nas redações do processo seletivo do Vestibular Indígena, e, por isso, imprimem conflitos e tensões na e para a constituição da identidade linguística do indígena - que ora se apresenta sob os princípios da Diversidade Cultural (inclusão), ora sob o efeito da desigualdade, da inferioridade e da tutela das ações do Estado (exclusão). Para tanto, elegemos como corpus as redações do $X$ Vestibular para os Povos Indígenas no Paraná dos candidatos aprovados e dos da lista de espera que optaram pela Universidade Estadual de Maringá (UEM), sob o escopo da Linguística, dos Estudos Culturais e da Análise do Discurso orientada pelas noções foucaultianas.

Em se tratando das identidades linguísticas, é importante definir as funções das línguas indígenas e da língua portuguesa, uma vez que estas atuam de diferentes formas na sociedade indígena e na não indígena. Além disso, não podemos deixar de considerar a intrínseca relação entre língua/ cultura/identidade ${ }^{2}$. As línguas indígenas se limitam ao seu território e às relações interpessoais indígenas, enquanto a língua portuguesa implica a possibilidade de cidadania - porque é a língua da Constituição e das leis, por isso, seu valor político, na identidade nacional e nas relações (in) formais. Nessa perspectiva, a língua indígena incide sobre a preservação linguística e cultural e a língua portuguesa funciona como um dispositivo
${ }^{2}$ Embora a língua seja compreendida como um elemento compositivo da cultura, a língua indígena perdeu fôlego conforme a identidade nacional se consolidava pela imposição da língua portuguesa. O mesmo se aplica à cultura indígena cujas práticas (usos e costumes) também sofreram alterações. Dentre os itens que configuram a etnia, quais sejam: língua, corpo e terra, estes dois últimos ainda persistem com um pouco mais de força e contribuem para a formação da identidade étnica do indígena brasileiro. 
de inclusão e de possibilidade de dignidade na sociedade não indígena. A língua portuguesa na qualidade de oficial e de nacional é condição para a inclusão e para o reconhecimento do indígena como membro da nação brasileira.

Dadas as funções que as línguas exercem, temos entendido que o nacional se projeta na e pela língua portuguesa, enquanto o étnico projetase nas e pelas línguas indígenas ${ }^{3}$. No âmbito desse exercício, as diferenças culturais produzem desigualdade e distanciam as populações indígenas das não indígenas, em razão de a coexistência entre elas ser marcada pela hegemonia do nacional, contrapondo o princípio de igualdade proposto pela Diversidade Cultural. Em meio a esse jogo, nacional e étnico coexistem, mas não interagem entre si, bem como acontece nas relações sociais. Estar nesse conflito significa estar no entre lugares - ou seja, pertencer ou não a uma identidade cultural, ser reconhecido ou não como cidadão (TASSO, 2013, p. 43); muito embora apenas uma prevaleça e se imponha: a brasileira/ portuguesa. Nessas condições, os princípios das políticas de inclusão e de afirmação efetivam-se parcialmente, porque uma identidade nacional é também uma identidade cultural e nela convergem códigos de conduta, usos, costumes e, principalmente, a língua. Daí, a razão de a identidade nacional também se inscrever na ordem política, já que é construída pela historicidade das decisões e ações políticas - políticas estas que intervêm no social ao implementar leis que (re)configuram condutas.

\section{Identidade nacional e linguística: condição de cidadania}

As identidades nacional e linguística estão em relação direta com o político. Tanto a discursivização das tendências políticas que atravessaram os governos, quanto a institucionalização de uma língua são decorrentes de um processo histórico construído cultural, social e politicamente. O político, na condição de princípio organizador do social, se estabelece por relações de poder em que prevalece o mais forte e astuto. Nessa medida, a língua portuguesa não é a língua nacional e oficial por acaso, mas é herança de uma história de dominação de colonizadores portugueses sobre as populações indígenas e condição para que compreendamos a construção das identidades nacional e linguística levando em conta o funcionamento do político na história, a fim de "olharmos” com menos ingenuidade a condição cidadã do indígena a partir dos sentidos atribuídos a essas populações.

Os sentidos que constituem a brasilidade são, por esses elementos, construídos por uma ideia, já consolidada, de diversidade étnica na qual se incluem índios, africanos e europeus. Por essa composição, os brasileiros são muitos e, ao mesmo tempo, nenhum. Graças à perspectiva daquele que fala, seja o europeu falando do índio ou vice-versa, a brasilidade é construída a partir do olhar da diferença (ORLANDI, 2008), que concorre para uma dupla possibilidade, a de rejeição e a de aceitação. Assim, em meio
${ }^{3}$ Cabe observar que há a possibilidade, sobre tal aspecto, de uma discussão mais pontual e linguística sobre a variedade do português em uso na oralidade e na escrita pelo indígena, o que faremos em outra oportunidade. 
ao(s) regime(s) de olhar(es) que constitui(em) a identidade do brasileiro, não existe uma unidade consensual enquanto um regime que define o que é ser brasileiro e, sim, múltiplas formas de designá-lo, dentre as quais a de ser descendente de uma outra etnia ou nacionalidade, tal como: "sou descente de italianos” (espanhóis, alemães portugueses, japoneses, africanos e indígenas brasileiros...).

Isso posto, os sentidos relativos à identidade brasileira formam-se pela diferença e pela segregação, ideia pela qual se estabelece certa mobilidade, concebida por uma ordem em que os caracteres de formação da identidade nacional se apresentam, ora focalizando o interno (natural de, nacional), ora o externo (estrangeiro, de etnia diversa). Nessa dinâmica por uma busca de identidade, as fragilidades da composição identitária criam o movimento que obstrui a potencialidade de uma identidade étnica nacional. Assim, “a desordem é constitutiva da identidade do sujeito e do sentido” (ORLANDI, 2008, p. 26). É por meio desse jogo de olhares que se vai traçando, política e historicamente, o modo como o brasileiro é representado e (re)conhecido, independentemente de sua origem e de sua hereditariedade.

Nessa conjuntura, a falta de definição da identidade brasileira, dada pela multiplicidade de variáveis que a compõe, cria as condições de possibilidade para que as definições sejam fortuitas na esfera política, nos discursos que reverberam a história e nas relações interpessoais. Essa especificidade do brasileiro vai na contramão da unidade (cultural e linguística) da qual a identidade nacional precisa para se legitimar. Com efeito, a identidade e a cultura nacionais tendem à normalização a fim de consolidá-las. A língua, nesse processo de normalização, “funciona como definidora de identidades ao mesmo tempo em que possibilita/estabelece/ facilita as relações sociais entre os membros do grupo” (BISINOTO, 2006, p. 76). Hall (2003, p. 59) sustenta o fato de que "não importa quão diferentes seus membros possam ser em termos de classe, gênero ou raça, uma cultura nacional busca unificá-la numa identidade cultural, para representá-los todos como pertencendo à mesma e grande família nacional”.

Diante desses apontamentos, consideramos que a língua é elemento basilar na consolidação da nação e da identidade nacional. É por meio dela que os membros de um país se unem e se reconhecem constituindo, assim, o sentimento de nacionalidade. Por mediar as relações formais e informais, nas categorias oral ou escrita, a língua (nacional/oficial) não é apenas um instrumento de comunicação, é também uma tecnologia de organização social e política. Vale destacar que, no âmbito das tecnologias, a consequência do biopoder, segundo Foucault (2011, p. 156-157), está relacionada com a

importância crescente assumida pela atuação da norma, às expensas do sistema jurídico da lei. A lei não pode deixar de ser armada e sua arma 
por excelência é a morte; aos que a transgridem, ela responde, pelo menos como último recurso, com esta ameaça absoluta. A lei sempre se refere ao gládio. Mas um poder que tem a tarefa de se encarregar da vida terá necessidade de mecanismos contínuos, reguladores e corretivos. Já não se trata de pôr a morte em ação no campo da soberania, mas de distribuir os vivos em um domínio de valor e utilidade. Um poder dessa natureza tem de qualificar, medir, avaliar, hierarquizar, mais do que se manifestar em seu fausto mortífero; não tem que traçar a linha que separa os súditos obedientes dos inimigos do soberano, opera distribuições em torno da norma. Não quero dizer que a lei se apague ou que as instituições de justiça tendam a desaparecer; mas que a lei funciona cada vez mais como norma, e que a instituição judiciária se integra cada vez mais num contínuo de aparelhos (médicos, administrativos, etc.) cujas funções são sobretudo reguladoras. Uma sociedade normalizadora é o efeito histórico de uma tecnologia de poder centrada na vida.

A língua de uma nação envolve, sob essa configuração, todos os membros que a compõem, por isso, servir-se dela, independentemente das circunstâncias, é uma prática de pertencimento e de fidelidade. Daí a razão do por que dominar os saberes elementares da língua nacional para utilizá-la sociopoliticamente é fundamental no reconhecimento da cidadania, uma vez que a prática dos deveres e a consciência dos direitos convertem membros passivos em cidadãos ativos. Esse modo de tratamento nos revela, ainda mais claramente, a relação entre domínio da língua e educação, dado que o saber político possibilita a prática cidadã de forma ativa, quando o membro tem ciência de sua condição de cidadão.

\section{Diversidade Cultural e Cidadania: efeitos do político no social}

O domínio da língua, a educação, o saber político e a prática cidadã são elementares para a consolidação da inclusão, do respeito e da tolerância previstos pela cidadania. A relação entre o político e o social é, neste caso, influenciada pelas ações políticas instituídas pelo Estado, as quais são constituídas pelas políticas públicas linguísticas, de inclusão e de afirmação. Sob esse cenário, o Vestibular Indígena funciona como efeito prático das tendências políticas contemporâneas, cujo referencial alimentase nas noções de igualdade, estabelecidas pelos Direitos Humanos, contexto sob o qual a biopolítica emerge como modos de racionalizar as formas de governo (FOUCAULT, 2008). Tal regime é o que possibilita evocar e pensar a questão da diversidade sob a perspectiva cultural, bem como se estabelecer na "multiplicidade de formas pelas quais as culturas dos grupos e sociedades encontram sua expressão [...] transmitidas entre e dentro dos grupos e sociedades” (UNESCO, 2007, p. 04). Por isso, a Diversidade Cultural revela-se na coexistência da multiplicidade de culturas e na diversidade de modos de expressão dessas culturas. 
Assim, o princípio da Diversidade Cultural na biopolítica é fazer viver a diversidade e deixar morrer o monocultural. Segundo Carvalho e Faustino (2010, p. 17) o apelo à diversidade implica o combate aos preconceitos referentes ao gênero, à cor da pele, às tendências religiosas ou políticas, aos diversos tipos de deficiências, às culturas, às posições econômicas. Nessa medida, deixar morrer o monocultural significaria também deixar morrer as desigualdades que separam tão distantemente essas diferenças. Convém ressaltar que língua e cultura são praticamente indissociáveis, uma vez que esta se manifesta e se preserva (protege) na e pela prática linguística seja de uma etnia, seja de uma nação (considerando nesta os seus dialetos locais que, embora possam comprometer a comunicação não impedem que ela aconteça).

Para fazer viver a diversidade, é preciso criar as condições de existência para fazer viver a interação cultural, mediada pelo respeito à população indígena. Contudo, o que se tem apreendido sobre as questões étnicas é que, embora haja avanços legais, a mobilização de ações efetivas dessa ordem ainda é morosa. No convívio social, o que se percebe é um movimento contraditório de retorno ao biopoder, política de governo esta em cuja prática se projeta também a prática do colonialismo, nas palavras de Foucault (2008), no poder sobre a vida e a morte dos sujeitos - "fazer morrer e deixar viver” (FOUCAULT, 2008).

A cidadania, na condição de dispositivo da biopolítica, tecnologia do poder, "que lida com a população, e a população como problema político” (FOUCAULT, 1999, p. 292-293), favorece a manutenção do biopoder, uma vez que a cidadania não é exercida na sua plenitude, seja por parte do Estado, ao instituir a condição de tutela às populações indígenas; seja por parte dos próprios indígenas cuja barreira a ser vencida é a da proficiência da língua portuguesa.

\section{Um regime de olhar: a inconsistência do termo diferença}

O Vestibular Indígena constitui, na atualidade, uma oportunidade de os índios, integrantes das comunidades indígenas, disputarem vagas suplementares nas Universidades Estaduais e Federal paranaense, conforme Lei Estadual n 13.134/2001, modificada pela Lei Estadual n 14.995 de 2006. Atualmente, é realizado pelas instituições universitárias públicas paranaenses, a saber: Universidade Estadual de Londrina (UEL), Universidade Estadual de Maringá (UEM), Universidade Estadual do Norte do Paraná (UENP), Universidade Estadual de Ponta Grossa (UEPG), Universidade Federal do Paraná (UFPR), Universidade Estadual do Paraná (UNESPAR), Universidade do Centro-Oeste (UNICENTRO), Universidade Estadual do Oeste do Paraná (UNIOESTE). Para essas instituições de ensino superior são disponibilizadas um total de 52 vagas, sendo seis delas destinadas a 
cada uma das instituições estaduais do Paraná e dez, reservadas à Universidade Federal. A aplicação das provas desse vestibular é itinerante, segue um cronograma previamente acordado entre as instituições que integram as universidades públicas paranaenses, já nomeadas.

Em 2010, coube à Universidade Estadual de Maringá sediar o X Vestibular Indígena. Contudo, faz-se necessário destacar que a responsabilidade pela logística do evento foi e é delegada à CUIA Comissão Universidade para os Índios, instituída, no ano de 2001, pela SETI - Secretaria de Estado da Ciência, da Tecnologia e do Ensino Superior do Estado do Paraná para a execução anual desse acontecimento. Sob tal formato, em que logística e arquitetura organizam-se em torno dos princípios e diretrizes projetados pela CUIA, procedeu-se a realização do acontecimento X Vestibular para os Povos Indígenas no Paraná. Tratase, pois, de um conjunto de instrumentos projetados especificamente para a avaliação dos candidatos indígenas e conformados nas provas que compuseram o referido processo, divididas em duas categorias: oral e escrita. A primeira realizou-se por bancas compostas por dois avaliadores que, individualmente, atribuíram uma pontuação com base em dois critérios, conforme constava no manual do candidato: (i) capacidade de comentar os temas propostos no texto de maneira coerente; (ii) capacidade argumentativa e opinativa em relação ao texto lido. Cada um desses aspectos correspondia à metade da soma total dos pontos, cinquenta pontos. $\mathrm{Na}$ categoria escrita, segunda etapa do processo, foram realizadas as provas relativas às áreas: Língua Portuguesa - redação e interpretação de textos; Língua Estrangeira Moderna (Inglês ou Espanhol) ou Língua Indígena ${ }^{4}$ (Guarani ou Kaingang); Biologia; Física; Geografia; História; Matemática; Química. A prova de cada uma dessas áreas do conhecimento foi composta por cinco questões objetivas, com exceção da redação que atendeu a parâmetros específicos da língua escrita. Um ponto a ser destacado, nesse exame de seleção, é o fato de que, embora sejam provas que visam a atender às singularidades dessa população, o processo de avaliação teve seus critérios pautados no domínio da língua portuguesa. Tal procedimento manteve, assim, princípios harmônicos e coesos com a universidade que abriga e realiza o vestibular, dado que qualquer uma dessas Instituições de Ensino Superior do Paraná é tradicionalmente um espaço não indígena no âmbito social, cultural, político e linguístico. Aspectos que não podem ser desconsiderados no evento em questão.

De modo geral, como se pode observar até o momento, o evento Vestibular Indígena toma, em espaço institucional público paranaense, um formato revelador sobre o seu funcionamento, cujo princípio regulador inclui as noções de acontecimento, de série, de regularidade e de condição de possibilidade, as quais encerram um regime de olhar diferenciado do que se mantinha tradicionalmente em busca de determinar o ponto de

\footnotetext{
${ }^{4}$ Nos referirmos à(s) língua(s) indígena(s) no plural, dado que está implícita a diversidade étnica. Outro ponto que convém explicitar é que não temos o intuito de separar língua de cultura, uma vez que ambas são correlacionadas e codependentes.
} 
criação, a unidade de uma obra, de uma época ou de um tema, a marca da originalidade individual e o tesouro indefinido das significações ocultas.

No regime que aqui se propõe, o acontecimento do Vestibular Indígena é compreendido fora do "jogo de causas e de efeitos na unidade informe de um grande devir, homogêneo ou rigidamente hierarquizado" (FOUCAULT, 1996, p. 56). Por essa forma de entendimento, a operação que se colocou em prática foi a de dar um tratamento adequado à série composta pelo recorte, qual seja, todos os documentos relativos ao $\mathrm{X}$ Vestibular (2010), desde aqueles de ordem legal aos materiais das provas, que compreendem as questões e comandos e as resoluções respectivas, objetivas e subjetivas. Todo o conjunto de materiais que constitui o corpus deste trabalho teórico-analítico é acometido de relações convergentes que carregam em si significações que podem ser comuns a toda uma época. Assim, todo o empreendimento analítico desse vestibular atuou em permanente recorrência às séries diversas entrecruzadas, divergentes, cujo acontecimento foi passível de circunscrição que, ao se fazer emergir, e ao circunscrevê-lo, tornou possível descrever as condições de sua própria aparição, já que as noções de regularidade, casualidade, descontinuidade, dependência e transformação ligavam-se a esse acontecimento e às séries determinadas. Em termos foucaultianos, "é sempre no âmbito da materialidade que [o acontecimento] se efetiva, que é efeito; ele possui seu lugar e consiste na relação, coexistência, dispersão, recorte, acumulação, seleção de elementos materiais; não é o ato nem a propriedade de um corpo; produz-se como efeito de e em uma dispersão material” (FOUCAULT, 1996, p. 57-8). Nesse segmento, por considerar a descontinuidade dos acontecimentos é que pudemos observar e alinhavar as transformações das sociedades. No caso deste estudo, as transformações correspondem às alterações ocorridas no processo específico do vestibular, ano a ano, condições para que pudéssemos escavar as camadas que abrigaram, de uma duração a outra, de um domínio a outro, modos de construção que se fizeram reverberar o que é ser índio brasileiro na contemporaneidade.

Por conseguinte, as séries enunciativas de que tratamos, quando levadas a termo as suas descontinuidades, estão diretamente relacionadas com as produções escritas da prova de redação. Essas séries revelam, em sua conjuntura, cesuras de rompimento do instante e dispersam o sujeito em uma pluralidade de posições e de funções possíveis. Em outras palavras, o que se reconhece por esse processo, acaba por invalidar "as menores unidades tradicionalmente reconhecidas ou as facilmente contestadas: o instante e o sujeito” (FOUCAULT, 1996, p. 58).

Assim posto, os indígenas têm suas posições e funções redefinidas na sociedade contemporânea em razão dos acontecimentos que ampliaram os espaços de coexistência desses sujeitos, espaços estes, como as universidades, que ora se constituem como possibilidade de inclusão ora como 
reforço para a exclusão e a rejeição daquilo que ainda se preserva. Isso porque as diferenças entre indígenas e não indígenas estão demarcadas no corpo, por traços fisionômicos e adereços; na língua, pelas inúmeras dificuldades no domínio da língua portuguesa e pela segregação entre o que é nacional e oficial; e na cultura, rompendo com as expectativas e exigências do universo acadêmico. O Vestibular é o acontecimento e as redações decorrentes do Vestibular (2010) são, por suas condições de existência, a materialidade discursiva componente da série e do objeto de análise, as quais visavam a atender ao enunciado-comando da prova, conforme o quadro 1 :

Quadro 1 - Comando da Prova de Redação do X Vestibular Indígena

\title{
REDAÇÃO
}

\begin{abstract}
Redija uma carta, endereçada ao Presidente da República Federativa do Brasil, para fazer suas reivindicações. Para isso, eleja duas preocupações que afetam o seu povo e estejam relacionadas com a língua indígena e com a área demarcada para os grupos indígenas. Utilize como apoio para sua carta os textos apresentados, bem como aqueles disponiveis na prova de Língua Portuguesa deste vestibular.

Sua carta deve conter, no mínimo, 12 e, no máximo, 18 linhas. Atente-se para o fato de que o texto produzido não pode apresentar registros ou marcas que identifiquem o candidato, dentre os quais o seu nome e a sua assinatura
\end{abstract}

Fonte: Relatório do X Vestibular Indígena (CUIA/UEM, 2010)

Para atender a este comando, o vestibulando teve auxílio de dois textos. Um dos textos versava sobre a terra e o outro, sobre a língua. Os gêneros de ambos os textos contribuíram para que se percebesse tanto a importância da língua escrita quanto às temáticas apresentadas; estratégia empregada a fim de que os candidatos estabelecessem relações com os saberes ali contemplados e avaliassem o papel que esses dois componentes têm na e para o exercício pleno da cidadania. Nessa atividade, a condição de produção para a elaboração da redação era a reivindicação acerca desses dois aspectos compositivos da identidade indígena: língua e terra. Com essa proposição, criou-se a expectativa de que os candidatos pudessem fazer uso autônomo, prudente e efetivo dos saberes sobre si e sobre a comunidade, desde que abordassem os dois aspectos em foco, uma vez que “aquilo que [foi] requerido para a construção de novos enunciados” teve por objetivo a possibilidade de formular e de formular indefinidamente, proposições novas (FOUCAULT, 1996, p. 30).

Sob esse comando, totalizaram 195 redações, das quais foram selecionadas dez. Seis delas foram produzidas pelos candidatos aprovados e quatro pelos da lista de espera. O critério de seleção das redações teve como determinante a instituição pela qual os candidatos optaram, no caso, a UEM. Das dez redações selecionadas, três compuseram o recorte estabelecido para a prática analítica desenvolvida e norteada pelos eixos genealógico e crítico (FOUCAULT, 1996). Pelo delineamento desses dois eixos, concebemos a existência de um fluxo enunciativo determinante de duas 
ordens, estas dotadas de forças de poder e de resistências que se entrelaçam e se costuram, numa trama justificada pelo acontecimento. Criam-se as condições de formulação do discurso, este que procede de um jogo de mediação universal, e se projeta por um movimento que, entre coerções, interdições supressões, fronteiras e limites; como se alçasse a ser aliviado “de sua parte mais perigosa e que sua desordem fosse organizada segundo figuras que esquivassem o mais incontrolável; tudo se passa como se tivessem querido apagar até as marcas de sua irrupção nos jogos do pensamento e da língua” (FOUCAULT, 1996, p. 50). Nesse espaço em que busca suspender a soberania do significante, os eixos crítico e genealógico fazem operar no discurso certos princípios que lhe possibilitam encontrar o verdadeiro da época, justamente porque esses princípios obedecem a regras, por sua vez, conformadas a um controle sobre essa produção do discurso, mecanismos que lhe fixam os limites. Por outro lado, a formulação enunciativa tende à rarefação do discurso, tendo em vista o fato de ele se acomodar a certas exigências e conceder ao sujeito do discurso a autorização para produzir formulações, tais como se apresentam - circunscritas à prática (e ao acontecimento) que responde ao seu princípio próprio de regularidade.

O movimento do discurso assim configurado projeta-se em forma de anéis semiabertos, já que o eixo crítico “procura cercar as formas de exclusão, da limitação, da apropriação [...]; mostrar como se formaram, para responder a que necessidades, como se modificaram e se deslocaram, que forças exerceram efetivamente, em que medida foram contornadas”. Desse modo, pretendeu-se avaliar como um discurso se deslocou e se rearticulou a partir das orientações do enunciado-comando da redação. De outra parte, o eixo genealógico é o que define o dizer e o regime ao qual se conforma ao se formular esse dizer. A formação efetiva dos discursos é concernida ao eixo genealógico, "quer no interior dos limites do controle, quer no exterior, quer, a maior parte das vezes, de um lado e de outro da delimitação” (FOUCAULT, 1996, p. 60-65). É importante destacar que a analítica mobilizada não desconsidera a condição de os dois eixos serem separados inteiramente, mas a possibilidade de eles se intercambiarem, ora os princípios de um eixo sejam empregados pelo outro e vice-versa. Assim, à presente analítica atribuímos a seguinte a proposição: o eixo genealógico orienta a produção escrita do vestibulando, consolidado na prática de avaliação; e o crítico orienta a produção do vestibulando, a partir do enunciado-comando.

Trata-se, pois, de um movimento que torna possível buscar o modo como os mecanismos de controle entram no jogo discursivo, revelando quais as regras de funcionamento do discurso e as formas construídas pela necessidade de se refletir sobre as estratégias empregadas para se dizer, como dizer e por que dizer certas coisas.

Nessa perspectiva, o método de análise põe à prova o dito, aquilo que está posto na visibilidade das redações, em uma constante investigação 
sobre o que está no jogo discursivo e seus efeitos. Ao pensar sobre os mecanismos que regulam a organização dos discursos, tal como propõe Foucault (1996), mobilizam-se alguns procedimentos externos de controle do discurso dentre os quais a vontade de verdade, que aqui é o que recebe maior atenção, porque ela se apoia sobre um suporte institucional. A vontade de verdade, nesses termos (FOUCAULT, 1996, p. 17), "é reconduzida, mais profundamente sem dúvida, pelo modo como o saber é aplicado em uma sociedade, como é valorizado, distribuído, repartido e de certo modo atribuído”. Orientadas por esse regime do olhar, projetamos o ponto de partida para análise das séries enunciativas contempladas abaixo:

\section{Redação 1}

Maringá, Paraná 17 de Dezembro de 2010.

Ilmo ao Excelêntíssimo Presidente da República Federativa do Brasil.

Luiz Inácio Lula da Silva

Nós, representantes do povo *, reunimos Maringá, estado do Paraná, para reinvindicar ao Governo Federal, através do ministério da Justiça/Fundação Nacional do Índio e Ministério da Educação a abertura imediata do processo de demarcação da terra indígena * e *, situado na cidade de *, uma vez que nós estamos em processo de confinamento humano onde nós não temos terras para nossa subsistência decidimos também solicitar um projeto para o fortalecimento da língua *, sendo que pela aproximidade da área urbana de *, contribuiu para a mudança cultural e lingüistica, fazendo que nosso povo perde principalmente a cultura e as nossas tradições.

Desde já...

Povo *

\section{Redação 2}

\section{Excelentíssimo Senhor Presidente da República}

Somos povos da etnia * do Estado *. Estamos cientes de que vivemos num mundo de constante evolução, tanto tecnológico como sócio-econômico e precisamos estar preparados para todo esse desenvolvimento acelerado. Sabemos que temos direitos e deveres enquanto cidadãos, mas somos um povo de cultura e tradições diferentes, com pensamentos e ideais próprios. Tradições e ideais, estes, que desde há muito tempo vem sendo sufocado e desrespeitado por interesses de poderosos e políticos individualistas que não estão preocupadas as diversidades de culturas e raças que o Brasil possui. Nos marginalizam e nos privam da inclusão social quando à reivindicamos.

Estamos crescendo em população e nos preocupa muito em como será o futuro de nossas crianças, pois não podem perder a sua identidade indígena. Nossas reservas indígenas já não comportam o aumento populacional. 
Queremos pedir aqui, mais uma vez, que seja respeitado um dos principais direitos, que a demarcação de nossas Terras. Só assim podemos preservar nossa identidade.

\section{Redação 3}

Nós da comunidade indígena *, nós preocupamos mesmo e com os brancos que cada vez mais estão invadindo a nossa reserva indígena. Com isso os proprios índios da comunidade, estão indo embora e só estão ficando os brancos, se continuar assim futuramente não haverá mais índios.

Outra coisa é a questão da língua os índios que sobraram, também estão querendo ensinar os filhos e os filhos. também não tem e nem fazem vontade de aprender, as crianças vão para a escola do branco aprender a cultura do branco a língua do branco, e esquece a cultura e a língua de origem se tornando assim para os índios brancos e assim muitas vezes são obrigados a ir embora da aldeia.

Primeiramente, cabe esclarecer que no decorrer da transcrição das redações optamos por substituir as identificações étnicas por um elemento simbólico, o asterisco $(*)$, a fim de evitar qualquer possibilidade de reconhecimento ou de juízo de valor que possa intervir na prática analítica. Sobre a transcrição das redações, importa explicitar que seus autores-vestibulandos indígenas tiveram seus nomes e sua colocação no resultado do vestibular preservados. Outro ponto a ser destacado é o de que os fragmentos de texto não passaram por quaisquer tipos de intervenção gramatical e/ ou ortográfica, posto que a proficiência da língua portuguesa é também um elemento da avaliação que põe à prova os saberes apreendidos no Ensino Fundamental e Médio. Nesse sentido, o Vestibular Indígena se configura como um ritual de passagem que traduz o movimento entre dois momentos fundamentais da educação no Brasil: o da saída do ambiente escolar de Ensino Médio e do ingresso na universidade pública. Por se tratar de um ritual, nele estão inscritas vontades de verdade nas quais os discursos estão enquadrados em uma ordem que avalia se estão de acordo ou não com o verdadeiro ou com o falso acerca do que é ser índio brasileiro na contemporaneidade e o que é ser índio brasileiro universitário na contemporaneidade. Em outras palavras, o ritual possui regras de funcionamento e regime próprio de verdade, os quais são determinantes para o processo de avaliação e valoração (pontos) das redações. Dentre as regras de funcionamento que esse ritual institui e a avalia, destacamos a proficiência em língua portuguesa, ainda que seja um vestibular específico para as populações indígenas.

Uma das regras de funcionamento discursivo é o enunciado-comando que controla o que se diz (terra e língua), para quem é dito (Presidente da República); e organiza o modo como será dito (gênero carta de reivindicação). Esse enunciado exerce, por congregar os procedimentos de descontinuidade, singularidade e exterioridade, o controle sobre o modo como 
os sujeitos redatores formularam os enunciados da redação. Desse modo, cria-se, pelo eixo, genealógico, as condições de possibilidade enunciativa para a modalidade “prova de redação escrita”. Em contrapartida, o eixo crítico tem o papel de atender ao enunciado-comando, condição de existência para formulação enunciativa sob duas vertentes: o que se enuncia tende a se encaixar no verdadeiro da época, sustentado pelos saberes institucionais da ordem do jurídico, da legalidade; ou, de outro modo, pelo imaginário de que o outro, a quem se dirige, sensibiliza-se com a causa e questões indígenas, objeto de problematização social, política, cultural e educacional. Nessa conjuntura, os enunciados componentes das redações são organizados por procedimentos de rarefação, de reagrupamento e de unificação dos discursos. Formato arquitetônico em que as redações produzidas pelos candidatos funcionam em aliança, conforme Diagrama 1.

Diagrama 1 - Análise das redações a partir do eixo genealogico e eixo crítico

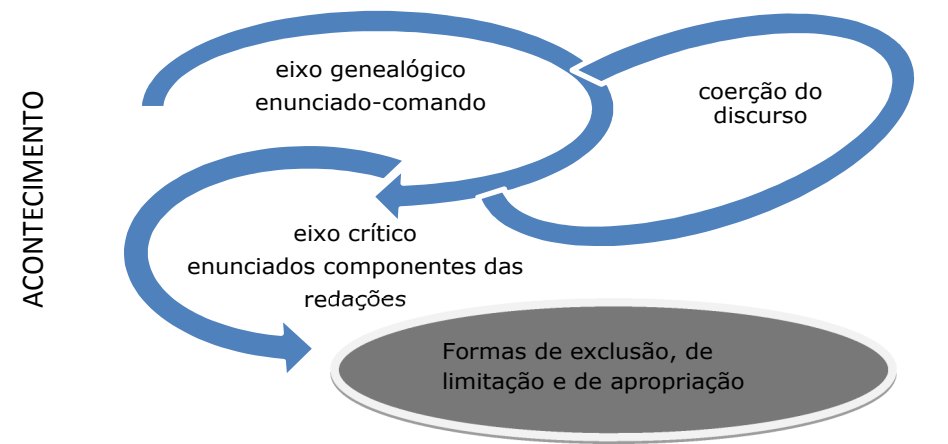

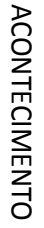

Fonte: Elaborado pelas autoras

\begin{tabular}{|c|c|c|c|}
\hline \multirow{2}{*}{$\begin{array}{l}\text { EIXO } \\
\text { GENEALÓGICO }\end{array}$} & \multicolumn{3}{|l|}{ EIXO CRÍTICO } \\
\hline & Redação 1 & Redação 2 & Redação 3 \\
\hline $\begin{array}{l}\text { Língua } \\
\text { “[...] eleja duas } \\
\text { preocupações que } \\
\text { afetam seu povo e } \\
\text { estejam relacionadas } \\
\text { com a língua } \\
\text { indígena e com a } \\
\text { área demarcada para } \\
\text { os grupos indígenas.” } \\
\text { (grifo nosso) }\end{array}$ & $\begin{array}{l}\text { “fortalecimento da } \\
\text { língua”; } \\
\text { “aproximidade da } \\
\text { área urbana de *, } \\
\text { contribuiu para a } \\
\text { mudança cultural e } \\
\text { lingüistica”. }\end{array}$ & $\begin{array}{l}\text { "somos um povo de cultura } \\
\text { e tradições diferentes, } \\
\text { com pensamentos e ideais } \\
\text { próprios". }\end{array}$ & $\begin{array}{l}\text { “Outra coisa é a questão da } \\
\text { língua os índios que sobraram, } \\
\text { também estão querendo ensinar } \\
\text { os filhos e os filhos. também } \\
\text { não tem e nem fazem vontade } \\
\text { de aprender, as crianças } \\
\text { vão para a escola do branco } \\
\text { aprender a cultura do branco a } \\
\text { língua do branco, e esquece a } \\
\text { cultura e a língua de origem”. }\end{array}$ \\
\hline
\end{tabular}


conclusão

\begin{tabular}{|c|c|c|c|}
\hline \multirow{2}{*}{$\begin{array}{l}\text { EIXO } \\
\text { GENEALÓGICO }\end{array}$} & \multicolumn{3}{|l|}{ EIXO CRÍTICO } \\
\hline & Redação 1 & Redação 2 & Redação 3 \\
\hline $\begin{array}{l}\text { Terra } \\
\text { “[...] eleja duas } \\
\text { preocupações que } \\
\text { afetam seu povo e } \\
\text { estejam relacionadas } \\
\text { com a língua indígena } \\
\text { e com a área } \\
\text { demarcada para os } \\
\text { grupos indígenas.” } \\
\text { (grifo nosso) }\end{array}$ & $\begin{array}{l}\text { "abertura imediata } \\
\text { do processo de } \\
\text { demarcação da terra } \\
\text { indígena * } \mathrm{e}^{*} \text { ”. }\end{array}$ & $\begin{array}{l}\text { "Estamos crescendo em } \\
\text { população e nos preocupa } \\
\text { muito”; } \\
\text { “Nossas reservas indígenas } \\
\text { já não comportam o aumento } \\
\text { populacional } \\
\text { demarcação de nossas Terras. } \\
\text { Só assim podemos preservar } \\
\text { nossa identidade”. }\end{array}$ & $\begin{array}{l}\text { “os brancos que cada vez mais } \\
\text { estão invadindo a nossa reserva } \\
\text { indígena. Com isso os proprios } \\
\text { índios da comunidade, estão } \\
\text { indo embora e só estão ficando } \\
\text { os brancos, se continuar assim } \\
\text { futuramente não haverá mais } \\
\text { índios”. }\end{array}$ \\
\hline $\begin{array}{l}\text { Reivindicações } \\
\text { “redija, uma } \\
\text { carta, endereçada } \\
\text { ao Presidente da } \\
\text { República Federativa } \\
\text { do Brasil, para fazer } \\
\text { suas reivindicações.” }\end{array}$ & $\begin{array}{l}\text { “reinvindicar ao } \\
\text { Governo Federal, } \\
\text { através do ministério } \\
\text { da Justiça/Fundação } \\
\text { Nacional do Índio } \\
\text { e Ministério da } \\
\text { Educação'; } \\
\text { “solicitar um projeto } \\
\text { para o fortalecimento } \\
\text { da língua *”. }\end{array}$ & $\begin{array}{l}\text { “precisamos estar } \\
\text { preparados para todo esse } \\
\text { desenvolvimento acelerado”, } \\
\text { “Sabemos que temos } \\
\text { direitos e deveres enquanto } \\
\text { cidadãos, mas somos um } \\
\text { povo de cultura e tradições } \\
\text { diferentes”; } \\
\text { “Tradições e ideais, estes, } \\
\text { que desde há muito tempo } \\
\text { vem sendo sufocado e } \\
\text { desrespeitado por interesses } \\
\text { de poderosos e políticos } \\
\text { Queremos pedir aqui, mais } \\
\text { uma vez, que seja respeitado } \\
\text { um dos principais direitos”. }\end{array}$ & \\
\hline
\end{tabular}

O Quadro 2 ilustra esse movimento. Nele se encontram os enunciados que se reportam tanto para os procedimentos do eixo genealógico quanto àqueles que têm correspondência com o eixo crítico. Tal organização dá visibilidade para o modo de formular dos enunciados e o modo como estes mesmos enunciados atendem a regras singulares de coerção discursiva.

Os enunciados, tais como se encontram dispostos no Quadro 1, na coluna correspondente ao eixo crítico "reivindicações”, acentuam os princípios da condição cidadã do indígena brasileiro, estabelecendo quais diferenças, no âmbito social, nivelam e padronizam os sujeitos cultural e linguisticamente. Conduta que procede à construção do efeito de unidade de uma nação. Ser cidadão corresponde ao que se concebe por verdadeiro na ordem do nacional e do político, cujas regras de funcionamento se sustentam nos princípios da igualdade e da Diversidade Cultural. No entanto, 
na ordem do social, o verdadeiro se estabelece pelo conflituoso convívio do que é étnico e do que é nacional.

As produções, ainda que sejam cartas de reivindicação, não possuem valor político nem social, uma vez que não estão filiados a uma instituição e não estão vinculadas a uma doutrina, apenas simulam tal condição. A falta de pertença doutrinária

questiona ao mesmo tempo o enunciado e o sujeito que fala, e um através do outro. Questiona o sujeito que fala através e a partir do enunciado, como provam os procedimentos de exclusão e os mecanismos de rejeição que entram em um jogo quando um sujeito que fala formula um ou vários enunciados inassimiláveis [...] a doutrina questiona os enunciados a partir dos sujeitos que falam, na medida em que a doutrina vale sempre como o sinal, a manifestação e o instrumento de uma pertença prévia - pertença de classe, de status social ou raça, de nacionalidade ou de interesse, de luta, de revolta, de resistência ou de aceitação. A doutrina liga os indivíduos a certos tipos de enunciação e lhes proíbe, consequentemente todos os outros; mas, ela se serve, em contrapartida, de certos tipos de enunciação para ligar individualmente entre si e diferenciá-los, por isso mesmo, de todos os outros. A doutrina realiza uma dupla sujeição: dos sujeitos que falam aos discursos e dos discursos ao grupo, ao menos virtual, dos indivíduos que falam (FOUCAULT, 1996, p. 42-43).

A doutrina, sob tais condições de produção, é condição para a rarefação dos discursos que desautoriza as reivindicações indígenas pela falta de pertença doutrinária. Como efeito disso, a falta de soluções para a problemática da língua e da terra não conferem valor de verdade às produções. Isso se deve a duas razões: (i) por se tratar de uma avaliação, constitutiva do Vestibular, no qual o indígena é um candidato à vaga nas universidades; (ii) pelo efeito contraditório da cidadania que se estabelece por um princípio nivelador: a igualdade - todos os cidadãos são iguais perante a lei e possuem direitos e deveres. Entretanto, a igualdade implica, muitas vezes, submissão cultural e linguística para a manutenção do nacional, silenciando as especificidades referentes a cada etnia indígena; assim, converte a identidade linguístico-cultural indígena aos padrões sociopolíticos nacionais.

Os fragmentos das redações revelam a insatisfação dos candidatos quanto às condições de existência da língua e da cultura. A sobrevivência dos aspectos que sustentam as identidades se consolida pela demarcação da terra. Por isso, as reivindicações sobre a terra são unívocas ao solicitar sua demarcação. A possibilidade de manutenção da língua aparece nos fragmentos como efeito da demarcação. As reivindicações sobre a língua e a terra como condição para a preservação das práticas culturais dos indígenas não correspondem às reivindicações do que se enquadra no nacional. O que se reclama, no âmbito nacional, é por menos corrupção a fim de 
proporcionar mais qualidade à saúde, à educação e à segurança. Isso porque o nacional já é marcado por uma língua e uma delimitação geográfica. Nessa perspectiva, étnico e nacional estão em relação de desigualdade, contrapondo-se aos princípios da Diversidade Cultural e da cidadania. Os procedimentos de exclusão e os mecanismos de rejeição põem em funcionamento a contradição do princípio de igualdade cujos efeitos comprometem a preservação das identidades linguísticas dos indígenas brasileiros.

\section{Considerações Finais}

Ao pôr à prova o jogo de significações prévias que definem diferença, desigualdade e diversidade, nos deparamos com o paradoxo que fragiliza o teor do princípio de igualdade que rege a Diversidade Cultural e a cidadania. Nessa conjuntura, os sujeitos da diversidade passam a ser concebidos sob os sentidos de inferioridade, de preconceito, de exclusão e de sujeição. Nessa direção, o respeito, como possibilidade de interação entre o étnico e o nacional, se traduz em uma tímida tolerância ao diverso.

A falta de consistência de soluções possíveis para a problemática da língua e da terra nas redações revelam procedimentos de exclusão que comprometem a identidade linguística do indígena. A falta de uma pertença doutrinária que autorize os sujeitos indígenas a dizer o que dizem, atribui ao dizer do indígena, verbalizado nas redações, o caráter de falso. A diferença é simulada pelo princípio de igualdade que, nas práticas sociais, se convertem em práticas de silenciamento, de sujeição e de exclusão.

\section{Referências}

BISINOTO, L. S. J. Identidade linguística o conceito em discussão. Línguas e Instrumentos linguísticos, Campinas, SP, n. 16, p. 73-86, 2006.

CARVALHO, E. G. de; FAUSTINO, R. C. Introdução. In: FAUSTINO, Rosangela Célia (Org.). Educação e diversidade cultural. Maringá: Eduem, 2010.

FOUCAULT, M. A ordem do discurso. Aula inaugural no Collège de France, pronunciada em 2 de dezembro de 1970. 12. ed. Tradução de Laura Fraga de Almeida Sampaio. São Paulo: Loyola, 1996.

FOUCAULT, M. Em defesa da sociedade: curso no Collège de France. Tradução de Maria Ermantina Galvão. São Paulo: Martins Fontes, 1999. (Coleção Tópicos).

FOUCAULT, M. Microfísica do poder. Organização e tradução de Roberto Machado. 11. ed. Rio de Janeiro: Graal, 1993.

FOUCAULT, M. Segurança, Território e população. Trad. de Eduardo Brandão. São Paulo: Martins Fontes, 2008. 
FOUCAULT, M. História da Sexualidade 1: A vontade de saber. Tradução de Maria Thereza da Costa de Albuquerque e J. A. Guilhon Albuquerque. São Paulo: Martins Fontes, 2011.

GONÇALVES, R. F. C. R. Cidadania, inclusão e biopolítica: a identidade linguística do indígena em contradição no processo seletivo Vestibular dos Povos Indígenas no Paraná. Dissertação (Mestrado)-Programa de Pós-Graduação em Letras. Universidade Estadual de Maringá, 2012.

HALL, S. Identidade cultural na pós-modernidade. Tradução de Tomaz Tadeu da Silva e Guaracira Lopes. 8. ed. Rio de Janeiro: DP\&A, 2003.

MANUAL DO CADIDATO do X VESTIBULAR DOS POVOS INDÍGENAS NO PARANÁ. COMISSÃO UNIVERSIDADE PARA OS ÍNDIOS. Disponível em: <http://www.vestibular.uem.br/indigenas/ manual\%20do\%20candidato.pdf>. Acesso em 24 mai. 2010.

ORLANDI, E P. Terra à vista: discurso do confronto: velho e novo mundo. 2. ed. Campinas, SP: Editora da UNICAMP, 2008.

RELATÓRIO DO X VESTIBULAR INDÍGENA. Comissão Universidade para os Índios/UEM, 2010.

TASSO, I. Olhares e dizeres da mídia sobre corpos em vigília: a fotografiadocumento e o inventário do real. In: LAGAZZI, Suzy; ROMUALDO, Edson Carlos; TASSO, Ismara (Org.). Estudos do texto e do discurso: o discurso em contrapontos: Foucault, Maingueneau, Pêcheux. São Carlos, SP: Pedro \& João. 2013, p. 41-64.

UNESCO. ORGANIZAÇÃO DAS NAÇÕES UNIDAS PARA A EDUCAÇÃO, A CIÊNCIA E A CULTURA. Convenção sobre a proteção e a promoção da Diversidade das Expressões Culturais. S.l.: UNESCO, 2007. (E-book).

Data de submissão: 07/04/2014

Data de aprovação: 14/07/2014 